\title{
The Challenges of Natural Algorithms
}

\author{
Bernard Chazelle \\ Department of Computer Science, \\ Princeton University
}

\begin{abstract}
This talk will sketch an algorithmic approach to the dynamics of living systems. Our working models consist of entropy-producing dissipative dynamic networks driven by a supply of free energy. They can be found in opinion dynamics, synchronization systems, and in many evolutionary contexts.

The main challenge posed by these "natural algorithms" is the dearth of analytical tools currently at our disposal. The focus of our work has been on building a new theory of endogenously-driven dynamic networks rich enough to allow for the renormalization of large-scale systems. The main novelty of our approach to dynamical systems is to make algorithms the centerpiece of the analysis.
\end{abstract}

\begin{abstract}
Short Bio
Bernard Chazelle is Eugene Higgins Professor of Computer Science at Princeton University, where he has been on the faculty since 1986. His current research focuses on the "algorithmic nature" of living systems. A professor at the Collège de France in Paris in recent years as well as a member of the Institute for Advanced Study in Princeton, he received his Ph.D in computer science from Yale University in 1980. The author of the book, "The Discrepancy Method," he is a fellow of the American Academy of Arts and Sciences, the European Academy of Sciences, and the recipients of three Best Paper awards from SIAM.
\end{abstract}

Permission to make digital or hard copies of part or all of this work for personal or classroom use is granted without fee provided that copies are not made or distributed for profit or commercial advantage and that copies bear this notice and the full citation on the first page. Copyrights for third-party components of this work must be honored. For all other uses, contact the Owner/Author(s). Copyright is held by the owner/author(s).

GECCO'16, July 20-24, 2016, Denver, Colorado, USA.

ACM ISBN 978-1-4503-4206-3/16/07.

DOI: http://dx.doi.org/10.1145/2908812.2908959 